\title{
QUALIDADE FÍSICA DE LATOSSOLOS AMARELOS SOB PLANTIO DIRETO NA REGIÃO DO CERRADO PIAUIENS ${ }^{(1)}$
}

\author{
Rossanna Barbosa Pragana ${ }^{(2)}$, Mateus Rosas Ribeiro ${ }^{(3)}$, Júlio César Azevedo Nóbrega ${ }^{(4)}$, \\ Mateus Rosas Ribeiro Filho ${ }^{(5)}$ \& Juliana Alves da Costa ${ }^{(6)}$
}

\begin{abstract}
RESUMO
O Cerrado vem sendo alvo de exploração sem a devida preocupação com a manutenção dos recursos naturais, e os sistemas de produção têm se caracterizado pelo uso intensivo do solo. $O$ objetivo desta pesquisa foi avaliar o efeito do plantio direto na alteração das características físicas de Latossolos Amarelos cultivados com soja. A pesquisa foi realizada na Serra do Quilombo, localizada no cerrado piauiense. Foram verificadas as alterações nos atributos do solo em decorrência da utilização agrícola, que foi iniciada com plantio convencional (PC), posteriormente substituído pelo sistema de plantio direto (PD). Foram amostrados solos com diferentes históricos de uso: PC7/PD8: sete anos de plantio convencional e oito de plantio direto; PC5/PD4: cinco anos de plantio convencional e quatro de plantio direto; PC3/PD3: três anos de plantio convencional e três de plantio direto; e CN: solo com cerrado nativo. As propriedades avaliadas foram: distribuição das frações granulométricas, argila dispersa em água, grau de floculação, relação silte/ argila, densidade do solo e das partículas, porosidade total, macro e microporosidade. Os resultados foram submetidos à análise de variância e, como análise complementar, utilizaram-se técnicas multivariadas. Para identificação das características físicas semelhantes do solo, utilizou-se a técnica de análise multivariada denominada análise fatorial. Maiores valores de densidade do solo e de microporosidade foram observados nos sistemas PD, e de macroporosidade e porosidade total, no $\mathrm{CN}$. Os resultados mostraram que a implementação do sistema plantio direto alterou o volume total de poros e a macroporosidade, porém estes apresentaram valores dentro da faixa considerada não restritiva. A análise fatorial
\end{abstract}

(1) Parte da Tese de Doutorado do primeiro autor apresentada à Universidade Federal Rural de Pernambuco- UFRPE. Recebido para publicação em 06 de junho de 2011 e aprovado em 10 de julho de 2012.

(2) Professora da Unidade Acadêmica de Serra Talhada, Universidade Federal Rural de Pernambuco - UFRPE. Fazenda Saco, s/ n. Caixa Postal 063. CEP 56900-000 Serra Talhada (PE). E-mail: rossannapragana@yahoo.com.br

(3) Professor Associado, Departamento de Agronomia, UFRPE R. Dom Manoel de Macedo s/n. Bairro Dois Irmãos. CEP 52171-900 Recife (PE). Bolsista do CNPq. E-mail: mrosas@depa.ufrpe.br

(4) Professor do Campus Professora Cinobelina Elvas (CPCE), Universidade Federal do Piauí, BR 135, Planalto Cibrazem. CEP 64900-000 Bom Jesus (PI). E-mail: juliocnobrega@gmail.com

(5) Professor Adjunto, Departamento de Agronomia, UFRPE. E-mail: mateusrf@depa.ufrpe.br

(6) Estudante de Agronomia, UFRPE. Bolsista de Iniciação Científica. E-mail: jualves_21@oi.com.br 


\begin{abstract}
possibilitou a visualização conjunta dos atributos do solo, sendo as propriedades densidade do solo, porosidade total e macroporosidade as que mais sofreram variação nos sistemas de uso.
\end{abstract}

Termos de indexação: atributos físicos do solo, sistema de manejo, degradação do solo, análise multivariada.

\title{
SUMMARY:PHYSICAL QUALITY OF OXISOLS UNDER NO-TILLAGE IN THE SAVANNA REGION OF PIAUI
}

\begin{abstract}
The Cerrado is being increasingly exploited in production systems characterized by intensive land use, without due concern for the preservation of natural resources. The objective of this research was to evaluate the effect of no-tillage soybean on the physical properties of Oxisols. The study was carried out in the region of "Serra do Quilombo", located in the Cerrado region of the State of Piaui. To assess changes in soil properties caused by agricultural use, soil samples were collected from conventional (CT) and no tillage (NT) areas with different use history; PC7/PD8 - seven years CT followed by eight years NT; PC5/PD4 - five years CT followed by four years NT; PC3/PD3-three years CT and three years NT; and NC-native cerrado vegetation. The results were subjected to variance analysis and multivariate techniques. Factorial analysis, a Multivariate Analysis technique, was used to identify similarities within soil physical properties. The evaluated soil properties were particle-size-distribution, water dispersible clay, clay flocculation degree, silt / clay ratio, bulk and particle density, total porosity, macro and microporosity. Greater bulk density and microporosity values were observed in NT and macroporosity and total porosity were higher under NC. The results showed that NT changed the total pore volume and macroporosity, however the values were not considered restrictive. The Factorial analysis enabled the combined visualization of soil properties, indicating that the soil properties bulk density, total porosity and macroporosity were most affected by the use systems.
\end{abstract}

\section{Index terms: soil physical properties, management systems, soil degradation, multivariate analysis}

\section{INTRODUÇÃO}

Os Cerrados do Piauí possuem uma área de 8,5 milhões de hectares, representando cerca de $30 \%$ da área total do Cerrado setentrional brasileiro (Aguiar \& Monteiro, 2005). Considerando que o Estado do Piaú apresenta-se como uma das últimas fronteiras agrícolas do Brasil, sistemas de manejo conservacionistas devem ser adotados nessa área para evitar perdas de solo, água e nutrientes.

Alguns atributos físicos do solo, como densidade, espaço poroso, resistência do solo à penetração, estabilidade de agregados, umidade volumétrica, água disponível e condutividade hidráulica, podem ser utilizados como indicadores da qualidade do solo, por variarem de acordo com o manejo a que o solo está sendo submetido. Nesse sentido, uma contínua avaliação dos atributos físicos do solo permite monitorar a eficiência ou não do sistema de manejo adotado (Rosa et al., 2003; Secco et al., 2005; Albuquerque et al., 2005; Vieira \& Klein, 2007).

Estudos evidenciaram que o sistema plantio direto (PD) tende a melhorar as propriedades físicas do solo à medida que os cultivos forem se sucedendo (Zambolim et al., 2001; Pereira et al., 2007). Entretanto, Rosa et al. (2003), avaliando aspectos físicos de um Latossolo Vermelho eutroférrico sob condições de PD e sob floresta nativa, obtiveram resultados que demonstram que a porosidade e a densidade do solo indicaram aumento da compactação do solo no sistema PD, quando comparado ao solo sob floresta nativa. Stone \& Silveira (2001) também concluíram que o sistema PD proporcionou maiores valores de densidade e microporosidade e, em consequência, menor porosidade total e macroporosidade, em comparação com solo de área nativa. Segundo Vieira \& Klein (2007), a utilização continuada do PD pode resultar em aumento da densidade, tendo como consequência a compactação do solo.

No sistema PD, o solo é submetido à menor tráfego, porém não é revolvido, tendendo à compactação superficial, que tem sido constatada pelo aumento da densidade do solo e da microporosidade e pela diminuição da porosidade total e, principalmente, da macroporosidade (Vieira et al., 2007; Klein et al., 2008). De acordo com Tormena et al. (2004), nos solos de textura argilosa e muito argilosa, a compactação das 
camadas superficiais constitui uma das limitações desses solos no PD. Nessas condições, tem-se adotado o revolvimento periódico do solo.

Secco et al. (2005) estudaram a densidade do solo, o espaço poroso e a produtividade das culturas de soja, trigo e milho em um Latossolo Vermelho argiloso, sob os sistemas de PD contínuo e com escarificação, preparo conservacionista e plantio convencional (PC). Os resultados demonstraram que a densidade do solo apresentou valores superiores nos tratamentos com menor mobilização do solo, enquanto a porosidade total e a macroporosidade mostraram comportamento inverso.

De acordo com o exposto, as desvantagens do PD são contornáveis. Portanto, esse sistema, quando bem empregado, poderá oferecer maior sustentabilidade ao agroecossistema. Contudo, essa afirmação não significa que o sistema PD seja uma solução para qualquer região ou tipo de solo. Segundo Bertoni \& Lombardi Neto (2008), o solo terá de apresentar condições mínimas de estrutura que permitam boa infiltração e ausência de camada de impedimento que dificulte a permeabilidade.

O solo é considerado um sistema complexo, resultante da interação de fatores geológicos, topográficos e climáticos, entre outros, que juntos formam indicadores (variáveis) que o caracterizam. Com a técnica da análise multivariada é possível explicar o máximo de intercorrelação entre as variáveis e descobrir quais delas contribuem mais para a caracterização e, ou, alteração do solo. Diversas pesquisas têm aplicado a técnica multivariada para análise de dados de solos (Freddi et al., 2008; Aratani et al., 2009; Carneiro et al., 2009; Pereira et al., 2010).

O objetivo deste trabalho foi analisar as alterações dos atributos físicos dos solos cultivados com soja em função de diferentes tempos de implantação do sistema $\mathrm{PD}$, após cultivo anterior em sistema de PC, confrontando os resultados com as características do solo de uma área de preservação com Cerrado nativo, a fim de identificar se o PD tem contribuído para melhorar a qualidade do solo após o PC.

\section{MATERIAL E MÉTODOS}

A área de estudo está localizada na Serra do Quilombo, no município de Bom Jesus-PI, que tem clima quente e semiúmido do tipo Aw (Köppen), com temperatura variando de 18 a $36{ }^{\circ} \mathrm{C}$. $\mathrm{Na}$ área predominam Latossolos Amarelos distróficos típicos, profundos e bem drenados, em relevo plano. Essa serra foi selecionada para o desenvolvimento do experimento porque tem grande importância econômica para o Estado do PI, em razão da sua grande extensão e relevo plano, excelentes condições para a expansão agrícola do Estado; além disso, é uma área carente de pesquisas científicas. O sistema de manejo do solo mais comumente utilizado no cerrado piauiense é o PC, porém o sistema PD está em expansão. Assim, foram selecionados talhões sob diferentes tempos de uso com plantio direto. No quadro 1 está descrito o histórico de uso dos solos das áreas estudadas e a localização geográfica.

Em cada área estudada (tratamentos), selecionada em função do tempo de implantação do sistema PD, e na área de vegetação nativa adjacente à área cultivada, que representou condição original do solo, foi aberto um perfil até a profundidade aproximada de $2 \mathrm{~m}$ e mais quatro minitrincheiras (até o horizonte $\mathrm{AB}$ ), de onde foram coletadas uma amostra deformada em cada minitrincheira e perfil, para realização das análises, e três indeformadas, para determinação da densidade do solo, nos horizontes $\mathrm{A}$ e $\mathrm{AB}$, cujas profundidades estão descritas no quadro 2. A amostragem foi considerada representativa em função da homogeneidade da área.

Após o preparo das amostras deformadas (TFSA), foi realizada a análise granulométrica pelo método da pipeta, com agitação mecânica em aparato de alta rotação, por $15 \mathrm{~min}$, seguindo método proposto por Embrapa (1997). O teor de argila dispersa em água foi determinado também pelo método da pipeta, sem a utilização de dispersante químico, e o grau de floculação da argila, calculado (Embrapa, 1997). A relação silte/ argila foi calculada a partir da divisão dos valores de silte pelos de argila total, obtidos na análise granulométrica. A densidade de partículas foi determinada pelo método do balão volumétrico.

Em amostras indeformadas, determinou-se a densidade do solo pelo método do anel volumétrico, com volume total de $250 \mathrm{~cm}^{3}$ (Embrapa, 1997). A porosidade total foi calculada pela relação entre as densidades do solo e de partículas. A microporosidade foi determinada pelo método do funil de Haines, aplicando-se sucção correspondente a uma coluna de água de $60 \mathrm{~cm}$. A macroporosidade foi calculada pela diferença entre a porosidade total e a microporosidade (Embrapa, 1997).

O delineamento experimental utilizado foi o inteiramente casualizado, em parcelas subdivididas, com cinco repetições, em que as parcelas correspondem às áreas com diferentes tempos de implantação do sistema PD e sob Cerrado nativo (PC3/PD3: plantio direto há três anos; $\mathrm{PC5} / \mathrm{PD} 4$ : plantio direto há quatro anos; PC7/PD8: plantio direto há oito anos; e CN: Cerrado nativo), e as subparcelas, às profundidades de amostragem, representadas pelos horizontes $\mathrm{A} \mathrm{e}$ $\mathrm{AB}$, indicadas no quadro 2 , da mesma classe de solo Latossolo.

Os resultados foram submetidos à análise de variância, sendo os efeitos da profundidade, do uso do solo e da interação uso do solo x profundidade comparados pelo teste de Tukey a $5 \%$, empregandose o programa computacional SAS/STAT (2002).

Como análise complementar, foi utilizada a técnica multivariada. Como os dados foram expressos em 
unidades de medidas diferentes, eles foram padronizados (média zero e variância 1) para assegurar que todas as variáveis contribuíssem igualmente para o modelo, independentemente da escala. A fim de identificar a similaridade das áreas com solos cultivados sob PD e solo sob vegetação nativa, utilizou-se como ferramenta a análise de agrupamento (análise de cluster-distância euclidiana). Os grupos foram definidos pelo traçado de uma linha paralela ao eixo horizontal, nas alturas de 3,5 e 4 , para os horizontes $\mathrm{A}$ e $\mathrm{AB}$, respectivamente, onde se encontram as maiores distâncias em que os grupos foram formados. Com a intenção de reduzir o grande número de variáveis para um conjunto mais significativo (representado pelos fatores), identificar quais variáveis pertencem a quais fatores e o quanto cada variável explica cada fator, foi feito o estudo da análise fatorial (AF) relacionado à análise de componentes principais (ACP). O critério adotado para a escolha do número de fatores foi selecionar

Quadro 1. Histórico de uso e localização de Latossolos Amarelos da Serra do Quilombo no sudoeste do Estado do Piauí

\begin{tabular}{|c|c|}
\hline Símbolo & Histórico \\
\hline $\mathrm{CN}$ & $\begin{array}{l}\text { Vegetação nativa de cerrado, sem histórico de interferência humana em termos de uso agrícola. Coordenadas } \\
09^{\circ} 10^{\prime} 40,85^{\prime} \mathrm{S} \text { e } 45^{\circ} 07^{\prime} 07^{\prime} \mathrm{W}\end{array}$ \\
\hline PC3/PD3 & $\begin{array}{l}\text { Manejo com PC (monocultura de soja desde o ano agrícola 2002/2003) até o ano agrícola 2004/2005. No ano } \\
\text { agrícola 2005/2006 foi implantado o sistema PD com cultivo de soja, sendo o milheto utilizado para formação } \\
\text { da palha. Em } 2007 / 2008 \text { foi cultivada com soja. Coordenadas } 09^{\circ} 11^{\prime} 48,7^{\prime \prime} \mathrm{S} \text { e } 45^{\circ} 08^{\prime} 14,2^{\prime \prime} \mathrm{W}\end{array}$ \\
\hline PC5/PD4 & $\begin{array}{l}\text { Monocultura de soja desde o ano agrícola 1999/2000. No ano agrícola 2004/2005 foi instalado o sistema PD, em } \\
\text { rotação anual de soja e milho, sendo no ano agrícola 2005/2006 cultivada com soja. Para o ano agrícola } 2006 / \\
2007 \text { foi cultivado milho e, em } 2007 / 2008 \text {, semeou-se soja. Coordenadas } 09^{\circ} 10^{\prime} 33,9^{\prime \prime} \text { S e } 45^{\circ} 08^{\prime} 20,4^{\prime} \text { W. }\end{array}$ \\
\hline $\mathrm{PC} 7 / \mathrm{PD} 8$ & $\begin{array}{l}\text { Área convertida em sistema agrícola no ano de } 1994 \text {, sendo desmatada e cultivada em sistema PC com } \\
\text { revolvimento intensivo de solo. No ano agrícola } 1997 / 1998 \text { foi cultivada com soja até o ano agrícola de } 2001 / \\
2002 \text {, quando foi introduzido o sistema PD com soja, utilizando o milheto na formação da palha. No ano } \\
\text { agrícola } 2004 / 2005 \text { foi estabelecida a rotação da área com milho nos anos pares e soja nos anos ímpares. No } \\
\text { ano agrícola } 2008 / 2009 \text { foi introduzida na área forrageira do gênero Brachiaria sp. após a colheita do milho. } \\
\text { Coordenadas } 09^{\circ} 10^{\prime} 48,8^{\prime} \mathrm{S} \text { e } 45^{\circ} 07^{\prime} 46,1^{\prime} \text { W. }\end{array}$ \\
\hline
\end{tabular}

CN: cerrado nativo; PC: plantio convencional; PD: plantio direto.

Quadro 2. Fração granulométrica, classe textural, argila dispersa em água (ADA), grau de floculação (GF) e relação silte/argila dos dois primeiros horizontes de Latossolos Amarelos, com diferentes tempos de implantação do sistema plantio direto e Cerrado nativo

\begin{tabular}{|c|c|c|c|c|c|c|c|}
\hline $\begin{array}{l}\text { Tratamento/ } \\
\text { Profundidade }\end{array}$ & Areia & Silte & Argila & Classe textural & ADA & GF & Silte/argila \\
\hline & & \multicolumn{2}{|l|}{$\mathrm{g} \mathrm{kg}^{-1}$} & & $\mathrm{~g} \mathrm{~kg}^{-1}$ & $\%$ & \\
\hline & & & & Horizonte A & & & \\
\hline $\mathrm{CN}(0-20 \mathrm{~cm})$ & $681 \mathrm{ABa}$ & $58 \mathrm{Aa}$ & $261 \mathrm{ABa}$ & franco-argiloarenosa & $111 \mathrm{~B} \mathrm{~b}$ & $56 \mathrm{Aa}$ & $0,22 \mathrm{Aa}$ \\
\hline PC7/PD8 $(0-16 \mathrm{~cm})$ & $657 \mathrm{Ba}$ & $56 \mathrm{Aa}$ & $287 \mathrm{Aa}$ & franco-argiloarenosa & $138 \mathrm{Ab}$ & $51 \mathrm{Aa}$ & $0,19 \mathrm{Aa}$ \\
\hline PC5/PD4 $(0-20 \mathrm{~cm})$ & $698 \mathrm{Aa}$ & $52 \mathrm{Aa}$ & $250 \mathrm{Ba}$ & franco-argiloarenosa & $130 \mathrm{ABb}$ & $48 \mathrm{Aa}$ & $0,21 \mathrm{Aa}$ \\
\hline \multirow[t]{2}{*}{ PC3/PD3 $(0-17 \mathrm{~cm})$} & $672 \mathrm{ABa}$ & $51 \mathrm{Aa}$ & $277 \mathrm{ABa}$ & franco-argiloarenosa & $126 \mathrm{ABb}$ & $53 \mathrm{Aa}$ & $0,18 \mathrm{Aa}$ \\
\hline & & & & Horizonte $\mathrm{AB}$ & & & \\
\hline $\mathrm{CN}(20-42 \mathrm{~cm})$ & $667 \mathrm{ABa}$ & $57 \mathrm{Aa}$ & $276 \mathrm{Aa}$ & franco-argiloarenosa & $150 \mathrm{Ba}$ & $45 \mathrm{Ab}$ & $0,21 \mathrm{Aa}$ \\
\hline PC7/PD8 $(16-44 \mathrm{~cm})$ & $645 \mathrm{Ba}$ & $56 \mathrm{Aa}$ & $299 \mathrm{Aa}$ & franco-argiloarenosa & $185 \mathrm{Aa}$ & $38 \mathrm{Ab}$ & 0,19 Aa \\
\hline PC5/PD4 (20-45 cm) & $677 \mathrm{Aa}$ & $54 \mathrm{Aa}$ & $269 \mathrm{Aa}$ & franco-argiloarenosa & $165 \mathrm{ABa}$ & $39 \mathrm{Ab}$ & $0,20 \mathrm{Aa}$ \\
\hline PC3/PD3 $(17-40 \mathrm{~cm})$ & $646 \mathrm{ABa}$ & $55 \mathrm{Aa}$ & $299 \mathrm{Aa}$ & franco-argiloarenosa & $172 \mathrm{ABa}$ & $42 \mathrm{Ab}$ & $0,18 \mathrm{Aa}$ \\
\hline CV (\%) & 2,13 & 7,53 & 5,29 & - & 7,68 & 8,63 & 9,96 \\
\hline
\end{tabular}

CN: Cerrado nativo; PC7/PD8: plantio direto há oito anos; PC5/PD4: plantio direto há quatro anos; e PC3/PD3: plantio direto há três anos. Médias seguidas pela mesma letra não diferem entre si pelo teste de Tukey a $5 \%$. Letras maiúsculas comparam os tratamentos dentro do mesmo horizonte, e letras minúsculas, os horizontes dentro do mesmo tratamento. 
aquelas que apresentaram autovalores acima de 1,00 e conseguiram sintetizar uma variância acumulada acima de $70 \%$. Nas análises estatísticas multivariadas foi utilizado o software STATISTICA versão 7.0 (Statsoft, 2004).

\section{RESULTADOS E DISCUSSÃO}

Observa-se no quadro 2 que não há diferença significativa das frações granulométricas do $\mathrm{CN}$ em relação aos tratamentos com $\mathrm{PD}$, indicando que o manejo adotado na área de estudo não alterou essas frações. Entretanto, nota-se que há variação significativa entre os tratamentos PC7/PD8 e PC5/ PD4 quanto à areia e argila, nos dois horizontes. Essa variação deve-se à natureza dos materiais de origem (sedimentos derivados de arenito e folhelho), o que provoca variabilidade espacial dessas frações. Contudo, o teor de areia mais elevado do PC5/PD4 não interferiu na densidade do solo (Ds), que, apesar de ter sido maior neste último, não diferiu estatisticamente dos demais tratamentos com solo cultivado.

Em profundidade, observa-se aumento de argila do horizonte $\mathrm{A}$ para o $\mathrm{AB}$ não significativo e similar entre todos os perfis, assim como não há diferença entre horizontes para as frações areia e silte. Pragana (2011) caracterizou e classificou os solos dos quatro tratamentos, constatando incremento de argila pouco expressivo em profundidade ao longo de todos os perfis, o que caracteriza Latossolos.

Observando os valores de argila dispersa em água (ADA), verificou-se que o $\mathrm{CN}$ apresentou o menor valor em comparação com as áreas cultivadas nos dois horizontes (Quadro 2). Segundo Costa et al. (2004), a correção da acidez altera a eletroquímica de solos tropicais de carga variável; consequentemente, o aumento do potencial elétrico superficial contribui para a dispersão de argila nos solos cultivados. Além da correção da acidez, a adição de fertilizantes também contribuiu para o aumento da ADA nas áreas cultivadas, devido ao efeito dispersante dos elementos químicos adicionados, a exemplo do potássio.

Para o GF, verificou-se diferença entre os horizontes, dentro do mesmo tratamento (Quadro 2). As alterações no $\mathrm{pH}$, no teor de matéria orgânicas e nos cátions do solo (Pragana, 2011) podem ter influenciado as forças de repulsão e atração entre partículas; entretanto, percebeu-se variação não significativa do $\mathrm{GF}$ nos horizontes $\mathrm{A}$ e $\mathrm{AB}$ entre tratamentos. Para a relação silte/argila, também visualizada no quadro 2 , não foi verificada alteração pelo manejo, não apresentando diferença entre os tratamentos - resultado esperado, porque essa é uma propriedade do solo inalterada pelo manejo; ademais, por se tratar de um Latossolo, também seria esperado que não houvesse diferença entre os horizontes.

No quadro 3 verifica-se que não houve diferença entre tratamentos para a densidade de partículas (Dp).
Essa equidade nos resultados da Dp e da relação silte/ argila entre os tratamentos confirma que o experimento foi conduzido com o mesmo solo e admite também a classificação do Latossolo. Alem disso, confirma que os efeitos significativos são resultados do manejo e não da variação do solo.

Houve efeito significativo do manejo sobre a Ds. O $\mathrm{CN}$ apresentou o menor valor de Ds nos dois horizontes, em comparação aos solos cultivados, que não diferiram estatisticamente entre si, evidenciando que os diferentes tempos de implantação do PD não contribuíram para melhorar a Ds alterada pelos anos de uso em sistema convencional que antecederam o PD. Observa-se diminuição na porosidade total (PT) nas áreas cultivadas, como consequência da redução da macroporosidade, resultando também no aumento da Ds nessas áreas (Quadro 3). Esses resultados devem estar associados com o tráfego de máquinas, implicando a destruição dos agregados, diminuindo consequentemente os macroporos e aumentando os microporos, originando assim uma matriz mais densa. Maiores valores de Ds e menores de macroporos em solos sob PD, em comparação com áreas preservadas, também foram constatados por diversos autores (Stone \& Silveira, 2001; Klein \& Libardi, 2002; Rosa et al., 2003; Vieira \& Klein, 2007).

O valor da Ds encontrada no horizonte A do $\mathrm{CN}$ $\left(0,97 \mathrm{Mg} \mathrm{m}^{-3}\right)$ foi relativamente baixo e muito próximo do valor de $0,93 \mathrm{Mg} \mathrm{m}^{-3}$ encontrado por Neves et al. (2007) em Latossolo Vermelho distrófico sob Cerrado nativo. De acordo com Reichert et al. (2003), a Ds crítica depende da classe textural do solo; assim, para solos franco-arenosos são definidas como críticas Ds de 1,70 a $1,80 \mathrm{Mg} \mathrm{m}^{-3}$. Considerando a classe textural dos solos estudados, todos os resultados apresentaram valores inferiores aos críticos, relatados pelos referidos autores (Quadro 3).

Comportamento semelhante ao da Ds ocorreu entre os tratamentos com solo cultivado para as variáveis PT, macro e microporosidade, diferindo estatisticamente do CN. Não houve diferença entre os tratamentos com solo cultivado, demonstrando novamente que os diferentes tempos de implantação do PD não contribuíram para melhorar esses atributos do solo em relação ao CN. De forma geral, a macroporosidade aumentou com a profundidade nos solos cultivados, concordando com resultados de Tormena at al. (2002), em que Latossolos Vermelhos distróficos, cultivados sob plantio direto, apresentaram maior macroporosidade em profundidade. Para a microporosidade, houve diferença significativa entre os tratamentos com solos cultivados e o $\mathrm{CN}$ no horizonte A, bem como entre as profundidades nos tratamentos com solos cultivados, sendo os maiores valores observados no horizonte superficial. A exposição dos horizontes superficiais ao tráfego de máquinas diminuiu a macroporosidade e, consequentemente, aumentou a microporosidade (Quadro 3). O manejo do solo alterou menos a PT e a macroporosidade nos horizontes $\mathrm{AB}$, exceto para o $\mathrm{PC} 5 /$ 
PD4, que diferiu do CN, embora não tenha alterado a microporosidade nesses horizontes.

De acordo com Tormena et al. (1998), valores de macroporos inferiores a $0,1 \mathrm{~m}^{3} \mathrm{~m}^{-3}$ alteram $\mathrm{o}$ desenvolvimento e a produção das culturas. Em solos sob elevados potenciais de água, com no mínimo esse valor de macroporos, a difusão de $\mathrm{O}_{2}$ às raízes não é impeditiva. Observa-se nos dados do presente trabalho que tanto a PT quanto a macroporosidade são superiores a 50 e $10 \%$, respectivamente, exceto o tratamento $\mathrm{PC} 5 / \mathrm{PD} 4$, quanto à $\mathrm{PT}$. Este último tratamento passou por cinco anos de PC, e os quatro anos de PD não foram suficientes para elevar essas variáveis ao nível do $C N$, até mesmo no horizonte $A B$. Entretanto, esses valores sugerem que a implantação do sistema PD expressa condições satisfatórias ao desenvolvimento da maioria das plantas, mesmo diferindo estatisticamente do $\mathrm{CN}$.

De acordo com o dendrograma de análise de cluster dos horizontes A e AB (Figura 1), observa-se que grupos semelhantes foram formados nos dois horizontes. Pela disposição no gráfico, indivíduos pouco distanciados são menos dissimilares do que os amplamente distanciados. Observa-se que tanto no horizonte A quanto no $\mathrm{AB}$ os tratamentos PC7/PD8 e PC3/PD3 apresentaram maior semelhança, por possuírem a menor distância euclidiana.

Nos horizontes A e AB foram formados três grupos. O grupo II é representado pelos tratamentos PC7/PD8 e PC3/PD3. Os tratamentos CN e PC5/PD4 formaram grupos distintos entre si e entre o grupo II. O solo do tratamento PC5/PD4 foi cultivado cinco anos com PC, o que contribuiu para alterar suas propriedades físicas, e sob PD foram quatro anos, tempo insuficiente para recuperar essas propriedades. Os dois tratamentos do grupo II foram agrupados por apresentarem semelhança entre si. O PC7/PD8, apesar dos sete anos de PC, os oito anos de PD tornaram este solo com características semelhantes às do $\mathrm{PC} 3 / \mathrm{PD} 3$, que apresenta menos tempo de cultivo. Observa-se que os tratamentos com solos sob PD formaram grupos distintos do $\mathrm{CN}$, confirmando os resultados verificados na comparação entre as médias pelo teste de Tukey para Ds, PT, macro e microporosidade, principalmente no horizonte A.

No quadro 4 encontram-se os autovalores e a variância explicada por cada fator, obtidos na análise fatorial. Observa-se que o primeiro e o segundo fator do horizonte A apresentaram autovalores acima de 1; eles explicam 56,78 e 15,75\% da variância total, respectivamente. Os dois fatores iniciais acumulam $72,53 \%$ da variância total dos dados. Já no horizonte $\mathrm{AB}$ foram os três primeiros fatores que apresentaram autovalores acima de 1: o primeiro fator explica $49,50 \%$ da variância total; o segundo, $21,90 \%$; e o terceiro, $13,55 \%$. Portanto, $84,95 \%$ da variabilidade dos dados é explicada por três fatores principais.

Pouco mais de $70 \%$ da variabilidade dos dados é explicada pelos dois primeiros fatores no horizonte $\mathrm{A}$ e mais de $80 \%$ por três fatores no horizonte $A B$, o que, de acordo com Cruz \& Regazzi (1994), é satisfatório para avaliação por meio da dispersão gráfica, em relação à primeira e segunda variáveis. Isso mostra que, de oito variáveis, passam-se a utilizar dois e três fatores, com 20 observações que representam o conjunto original, havendo, dessa forma, redução de

Quadro 3. Densidade do solo (Ds), densidade de partículas (Dp), porosidade total (PT), macroporosidade, microporosidade e carbono orgânico (CO) dos dois primeiros horizontes de Latossolos Amarelos, com diferentes tempos de implantação do sistema plantio direto e com Cerrado nativo

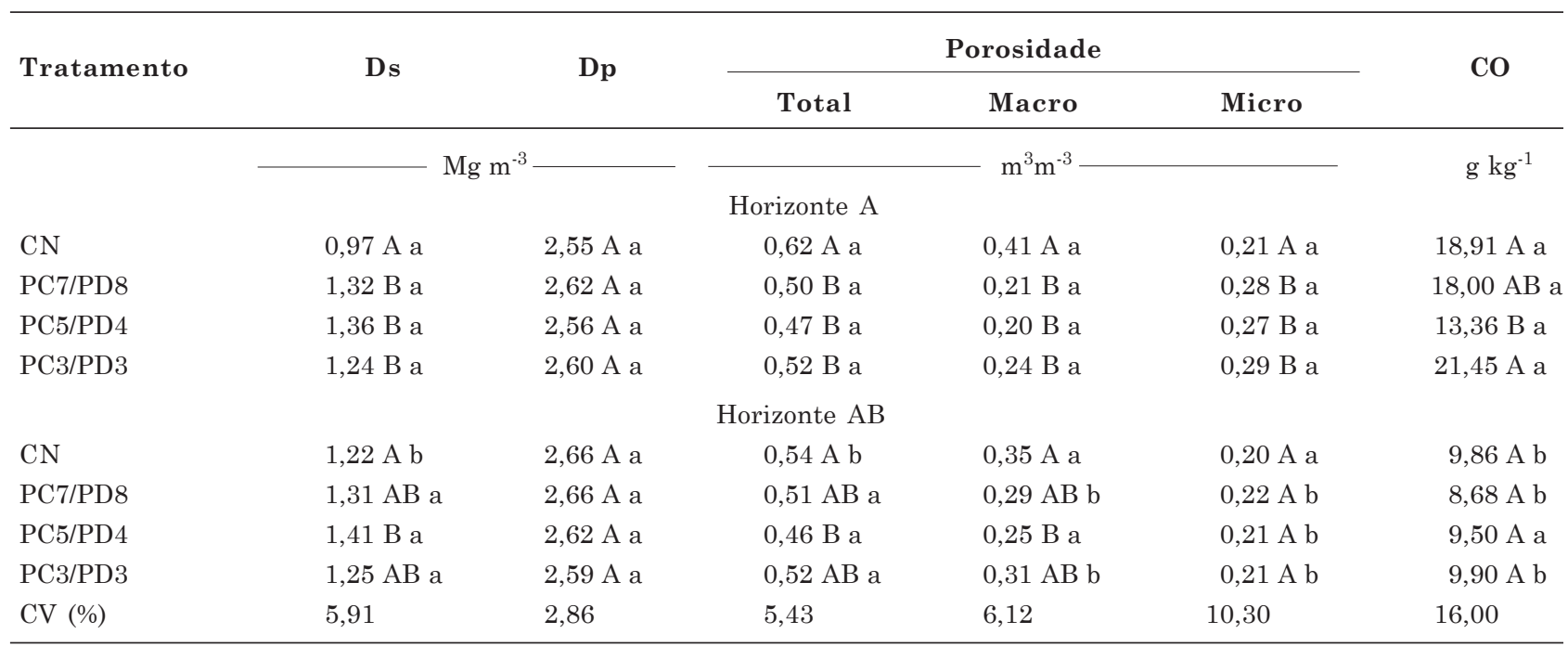

CN: Cerrado nativo; PC7/PD8: plantio direto há oito anos; PC5/PD4: plantio direto há quatro anos; e PC3/PD3: plantio direto há três anos. Médias seguidas pela mesma letra não diferem entre si pelo teste de Tukey a $5 \%$. Letras maiúsculas comparam os tratamentos, e letras maiúsculas, as profundidades dentro do mesmo tratamento. 
dimensionalidade das variáveis originais, com perda de explicação de menos de $30 \%(27,47 \%$ para o horizonte A e 15,05\% para o horizonte $\mathrm{AB}$ ).

As cargas fatoriais que definem quais variáveis são mais importantes para cada fator encontram-se no quadro 5 para os horizontes $\mathrm{A}$ e $\mathrm{AB}$. As variáveis que formam o fator 1 , tanto no horizonte A quanto no AB, são: Ds, PT e macroporosidade; o fator 2: GF e $\mathrm{ADA}$; e o fator 3 do horizonte AB é a Dp. Observa-se

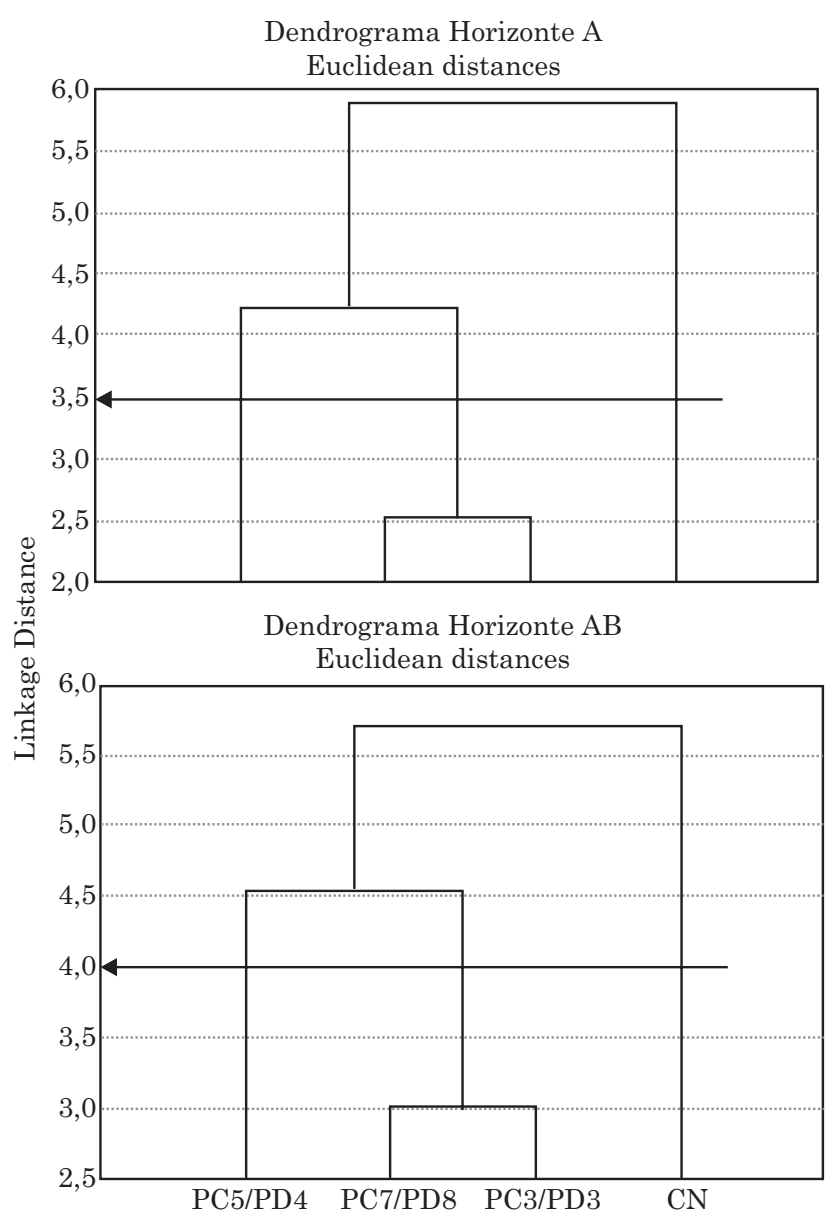

Figura 1. Dendrograma da análise de cluster dos horizontes A e AB.

Quadro 4. Autovalores e variância explicada por cada fator para os horizontes $\mathrm{A} \mathrm{e} \mathrm{AB}$

\begin{tabular}{ccccccc}
\hline \multirow{2}{*}{ Fator } & \multicolumn{2}{c}{ Horizonte $\mathbf{A}$} & & \multicolumn{2}{c}{ Horizonte $\mathbf{A B}$} \\
\cline { 2 - 3 } \cline { 6 - 6 } \cline { 5 - 6 } & Eigenvalue & \% Total & & Eigenvalue & \% Total \\
\hline 1 & 4,54 & 56,78 & & 3,96 & 49,50 \\
2 & 1,26 & 15,75 & & 1,75 & 21,90 \\
3 & 0,99 & 12,42 & & 1,08 & 13,55 \\
4 & 0,71 & 8,89 & & 0,72 & 9,04 \\
5 & 0,36 & 4,56 & & 0,40 & 5,06 \\
6 & 0,13 & 1,57 & & 0,07 & 0,93 \\
\hline
\end{tabular}

que as variáveis que apresentaram maior peso no modelo foram PT e Ds, nos dois horizontes.

Os resultados indicam que as variáveis Ds, PT, macroporosidade, GF e ADA que possuem cargas fatoriais elevadas e explicam a maior percentagem de variação são as que mais contribuem para alterar as características do solo em função do manejo, para os dois horizontes. Segundo Magalhães et al. (2009), os macroporos são os primeiros atingidos pela compactação do solo. As variáveis que apresentaram cargas fatoriais abaixo de 0,49 , ou seja, aquelas que retêm pequena parte da variação total, tanto para o horizonte A quanto para o $\mathrm{AB}$, foram relação silte/ argila, microporosidade e Dp - apesar de apresentar carga fatorial 0,96 no fator 3 do horizonte $A B$, este último fator explica a baixa percentagem de variação. Isso mostra que as variáveis mencionadas contribuem em menor proporção para discriminar o uso do solo.

Aplicando-se a ACP, foram obtidas as figuras $2 \mathrm{e}$ 3 , as quais representam o primeiro plano principal: a primeira, com a distribuição da nuvem de variáveis (indicadores); e a segunda, com a distribuição da nuvem de pontos (tratamentos). Essas figuras estão representando o fator 1, que é formado pelas variáveis Ds, PT e macroporosidade, em relação ao fator 2, representado pelas variáveis GF e ADA.

Variáveis que estão bem próximas do círculo unitário são as que mais contribuem para a variação, em relação às variáveis que estão mais afastadas. Verifica-se que as variáveis Ds, PT, macroporosidade, microporosidade, GF e ADA, que melhor representam o fator 1 em relação ao fator 2 , são aquelas que estão mais próximas do círculo unitário.

$\mathrm{Na}$ figura 3, pode-se verificar que os tratamentos estão distribuídos de acordo com a influência das

Quadro 5. Cargas fatoriais pelo método dos componentes principais para composição dos fatores, após rotação Varimax, para os horizontes $\mathrm{A}$ e $\mathrm{AB}$

\begin{tabular}{lccccccc}
\hline \multirow{2}{*}{ Variável } & \multicolumn{2}{c}{ Horizonte A } & & \multicolumn{3}{c}{ Horizonte AB } \\
\cline { 2 - 3 } \cline { 6 - 7 } & Fator $\mathbf{1}$ & Fator $\mathbf{2}$ & & Fator $\mathbf{1}$ & Fator 2 & Fator 3 \\
\hline Ds & $-0,94$ & 0,24 & & $-0,98$ & $-0,15$ & 0,04 \\
Dp & $-0,04$ & 0,01 & & 0,20 & $-0,14$ & 0,96 \\
PT & 0,94 & $-0,26$ & & 0,95 & 0,10 & 0,24 \\
Micropo & $-0,50$ & 0,18 & & $-0,27$ & $-0,24$ & $-0,01$ \\
Macropo & 0,87 & $-0,25$ & & 0,89 & 0,16 & 0,21 \\
SiltArg & 0,21 & 0,01 & & 0,14 & 0,23 & 0,12 \\
GF & 0,32 & $-0,91$ & & 0,34 & 0,89 & $-0,18$ \\
ADA & $-0,28$ & 0,82 & & $-0,02$ & $-0,84$ & 0,02 \\
Expl.Var & 3,00 & 1,73 & & 2,91 & 1,71 & 1,08 \\
Prp.Total & 0,37 & 0,22 & & 0,36 & 0,21 & 0,13 \\
\hline
\end{tabular}

Ds: densidade do solo; Dp: densidade de partículas; PT: porosidade total; micropo: microporosidade; macropo: macroporosidade; Siltarg: relação silte/argila; GF: grau de floculação; ADA: argila dispersa em água. 
variáveis em suas características. Analisando as figuras 2 e 3 simultaneamente, pode-se concluir que as variáveis do fator 1 mais significativas, como macroporosidade e PT, representam o tratamento $\mathrm{CN}$, e a Ds, os tratamentos com solos sob o sistema PD.

Os maiores valores de macroporosidade e de PT apresentados pelos solos do $\mathrm{CN}$, em relação aos solos sob sistema PD (Quadro 3) nos horizontes A e AB, foram demonstrados por meio da nítida tendência de agrupamento dos pontos que representam o tratamento $\mathrm{CN}$ à esquerda do diagrama (negativo) $\mathrm{e}$
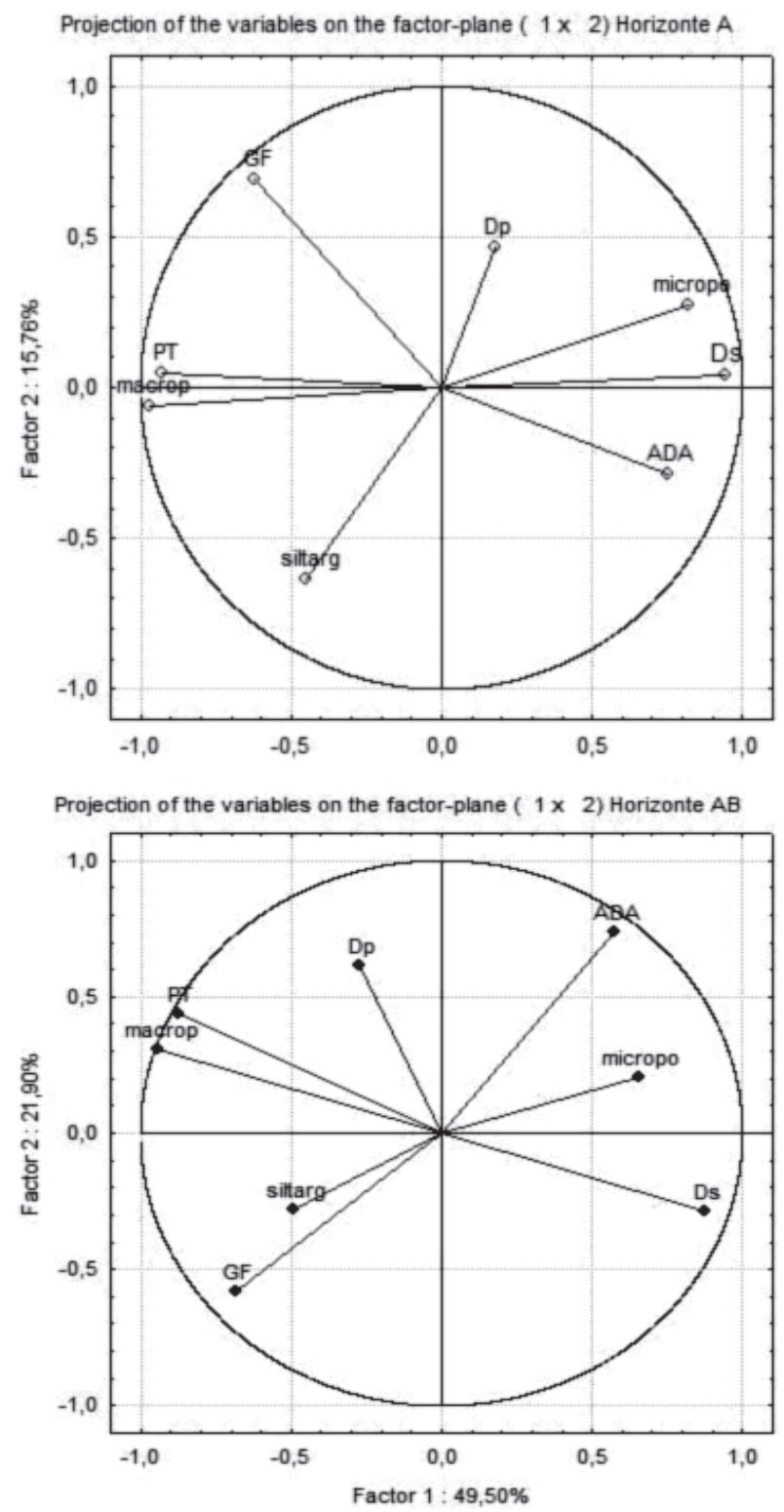

Figura 2. Gráfico da distribuição da nuvem de variáveis dos horizontes A e AB. Siltarg: relação silte/argila; GF: grau de floculação; macrop: macroporosidade; PT: porosidade total; Dp: densidade de partículas; ADA: argila dispersa em água; micropo: microporosidade; Ds: densidade do solo. dos solos sob sistemas $\mathrm{PD}$ no centro e à direita (positivo), confirmando o resultado do agrupamento (Figuras 1 e 3).

Os solos sob PD apresentaram Ds significativamente maior que o CN; ademais, a elevada Ds do PC5/PD4, em relação à de outros tratamentos (Quadro 3), também foi demonstrada com o agrupamento dos pontos que representam este tratamento à direita do diagrama (positivo), no terceiro quadrante, confirmando o agrupamento, que formou um grupo separado dos outros tratamentos com PD. Essa separação entre os tratamentos com $\mathrm{PD}$ e o $\mathrm{CN}$ indica claramente que o cultivo degrada o solo, quando comparado com o solo do CN.

Observa-se também que nos dois horizontes o tratamento PC5/PD4 está mais aglomerado no terceiro quadrante e os tratamentos PC7/PD8 e PC3/PD3 estão
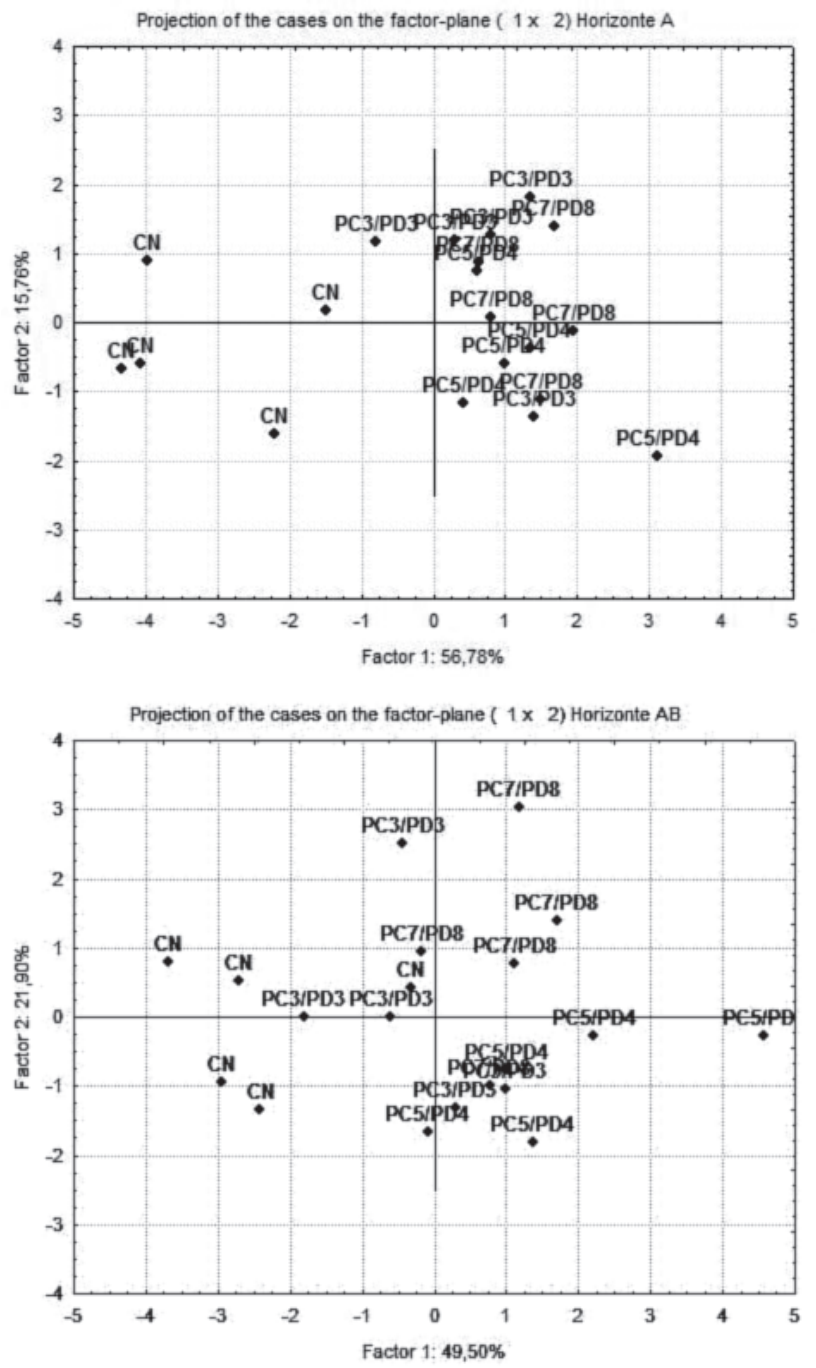

Figura 3. Gráfico da distribuição da nuvem de pontos dos horizontes A e AB. CN: Cerrado nativo; PD8: plantio direto há oito anos (PC7/PD8); PD4: plantio direto há quatro anos (PC5/PD4); e PD3: plantio direto há três anos (PC3/PD3). 
juntos, com predominância no primeiro e segundo quadrantes. O solo do tratamento PC5/PD4 tem quatro anos de cultivo sob PD, que foram antecedidos por cinco anos de PC. Os anos com PC contribuíram para a degradação do solo, e os quatro anos de PD ainda não recuperaram essa área. Esse histórico de uso do PC5/PD4 o diferencia dos tratamentos PC7/PD8, cujo solo está sob o cultivo de PD há oito anos, e do PC3/ PD3 há três anos, antecedidos por apenas três de PC. No horizonte AB, percebe-se que o cultivo do solo tem menor influência sobre a variância das variáveis, já que os ambientes apresentaram separação menos nítida (Figura 3), concordando com Carvalho Júnior et al. (1998) e Pereira et al. (2010). Esses resultados demonstram a concentração dos impactos com o cultivo no horizonte superficial do solo - efeito amplamente conhecido.

Independentemente do tempo de implantação e horizonte (A e AB), os solos manejados com o PD apresentaram comportamento similar, quando considerado o conjunto das variáveis em estudo - fato também determinado nos atributos avaliados pelo teste de médias. No entanto, com relação à área de $\mathrm{CN}$, o uso do solo provocou alteração em vários atributos estudados, o que pode levar à degradação destes com o tempo, como pode ser observado na figura 3 , pela separação nítida entre o $\mathrm{CN}$ e os tratamentos com PD. Por meio das técnicas multivariadas, foi possível identificar quais as variáveis que melhor se relacionaram com cada tipo de tratamento, quais as que provocaram maior efeito na alteração das características do solo, bem como o efeito do uso do solo na sua degradação.

\section{CONCLUSÕES}

1. A combinação entre o cultivo convencional e o plantio direto alterou os atributos físicos do solo em relação ao Cerrado nativo, notadamente no horizonte superficial.

2. A alteração da densidade do solo e do volume de poros dos solos cultivados evidencia o efeito negativo do uso do solo e a ineficiência da condução do sistema plantio direto em recuperar atributos físicos nas áreas estudadas, em virtude de diferentes anos (e intensidades) de impacto do sistema convencional.

3. As principais diferenças entre os solos cultivados e o solo do Cerrado nativo foram demonstradas pelas variáveis densidade do solo, porosidade total e macroporosidade, que explicam a maior percentagem de variação.

\section{LITERATURA CITADA}

AGUIAR, T.J.A. \& MONTEIRO, M.S.L. Modelo agrícola e desenvolvimento sustentável: A ocupação do Cerrado Piauiense. Amb. Soc., 8:1-18, 2005.
ALBUQUERQUE, J.A.; ARGENTON, J.; BAYER, C.; WILDNER, L.P. \& KUNTZE, M.A.G. Relação de atributos do solo com a agregação de um Latossolo Vermelho sob sistemas de preparo e plantas de verão para cobertura do solo. R. Bras. Ci. Solo, 29:415-424, 2005.

ARATANI, R.G.; FREDDI, O.S.; CENTURION, J.F. \& ANDRIOLI, I. Qualidade física de um Latossolo Vermelho Acriférrico sob diferentes sistemas de uso e manejo. R. Bras. Ci. Solo, 33:677-687, 2009.

BERTONI, J. \& LOMBARDI NETO, F. Conservação do solo. 6.ed. São Paulo, Ícone, 2008. 355p.

CARNEIRO, M.A.C.; SOUZA, E.D.; REIS, E.F.; PEREIRA, H.S. \& AZEVEDO, W.R.R. Atributos físicos, químicos e biológicos de solo de cerrado sob diferentes sistemas de uso e manejo. R. Bras. Ci. Solo, 33:147-157, 2009.

CARVALHO JÚNIOR, I.A.; FONTES, L.E.F. \& COSTA, L.M. Modificações causadas pelo uso e a formação de camadas compactadas e, ou, adensadas em um Latossolo Vermelhoescuro textura média, na região do cerrado. R. Bras. Ci. Solo, 22:505-514, 1998.

COSTA, F.S.; BAYER, C.; ALBUQUERQUE, J.A. \& FONTOURA, S.M.V. Calagem e as propriedades eletroquímicas e físicas de um Latossolo em plantio direto. Ci. Rural, 34:281-284, 2004.

CRUZ, C.D. \& REGAZZI, A.J. Modelos biométricos aplicados ao melhoramento genético. Viçosa, MG, Universidade Federal de Viçosa, 1994. 394p.

EMPRESA BRASILEIRA DE PESQUISA AGROPECUÁRIA EMBRAPA. Serviço Nacional de Levantamento e Conservação de Solo. Manual de métodos de análise de solo. Rio de Janeiro, 1997. 212p.

FREDDI, O.S.; FERRAUDO, A.S. \& CENTURION, J.F. Análise multivaria na compactação de um Latossolo Vermelho cultivado com milho. R. Bras. Ci. Solo, 32:953-961, 2008.

KLEIN, V.A. \& LIBARDI, P.L. Condutividade hidráulica de um Latossolo Roxo, não-saturado, sob diferentes sistemas de uso e manejo. Ci. Rural, 32:945-953, 2002.

KLEIN, V.A.; VIEIRA, M.L.; DURIGON, F.F.; MASSING, J.P. \& FÁVERO, F. Porosidade de aeração de um Latossolo Vermelho e rendimento de trigo em plantio direto escarificado. Ci. Rural, 38:365-371, 2008.

MAGALHÃES, E.N.; OLIVEIRA, G.C.; SEVERIANO, E.C.; COSTA, K.A.P. \& CASTRO, M.B. Recuperação estrutural e produção do capim-tifton 85 em um Argissolo VermelhoAmarelo compactado. Ci. Animal Bras., 10:68-76, 2009.

NEVES, C.M.N.; SILVA, M.L.N.; CURI, N.; CARDOSO, E.L.; MACEDE, R.L.G.; FERREIRA, M.M. \& SOUZA, F.S. Atributos indicadores da qualidade do solo em sistema agrossilvopastoril no noroeste do estado de Minas Gerais. Sci. For., 74:45-53, 2007.

PEREIRA, A.A.; HUNGRIA, M.; FRANCHINI, J.C.; KASCHUK, G.; CHUEIRE, L.M.O.; CAMPO, R.J. \& TORRES, E. Variações qualitativas e quantitativas na microbiota do solo e na fixação biológica do nitrogênio sob diferentes manejos com soja. R. Bras. Ci. Solo, 31:1397$1412,2007$. 
PEREIRA, S.A.; OLIVEIRA, G.C.; SEVERIANO, E.C.; BALBINO, L.C. \& OLIVEIRA, J.P. Análise de componentes principais dos atributos físicos de um Latossolo Vermelho Distrófico típico sob pastagem e mata. Global Sci. Technol., 3:87-97, 2010.

PRAGANA, R.B. Caracterização pedológica e diagnóstico da qualidade de solos sob plantio direto na Serra do Quilombo, Sudoeste Piauiense. Recife, Universidade Federal Rural de Pernambuco, 2011. 159p. (Tese de Doutorado)

REICHERT, J.M.; REINERT, D.J. \& BRAIDA, J.A. Qualidade dos solos e sustentabilidade de sistemas agrícolas. Ci. Amb., 27:29-48, 2003.

ROSA, M.E.C.; OLSZEVSKI,' N.; MENDONÇA, E.S.; COSTA, L.M. \& CORREIA, J.R. Formas de carbono em Latossolo Vermelho Eutroférrico sob plantio direto no sistema biogeográfico do cerrado. R. Bras. Ci. Solo, 27:911-923, 2003.

SAS/STAT: Software: Changes and enhancements through release 9.1. Cary, SAS Institute, 2002.

SECCO, D.; DA ROS, C.O.; SECCO, J.K. \& FIORIN, J.E. Atributos físicos e produtividade de culturas em um Latossolo Vermelho argiloso sob diferentes sistemas de manejo. R. Bras. Ci. Solo, 29:407-414, 2005.
STATSOFT, INC. Statistica for Windows - Computer program manual. Tulsa, 2004.

STONE, L.F. \& SILVEIRA, P.M. Efeitos do sistema de preparo e da rotação de culturas na porosidade e densidade do solo. R. Bras. Ci. Solo, 25:395-401, 2001.

TORMENA, C.A.; BARBOSA, M.C.; COSTA, A.C.S. \& GONÇALVES, C.A. Densidade, porosidade e resistência à penetração em Latossolo cultivado sob diferentes sistemas de preparo do solo. Sci. Agric., 59:795-801, 2002.

TORMENA, C.A.; FRIEDRICH, R; PINTRO, J.C.; COSTA, A.C.S. \& FIDALSKI, J. Propriedades físicas e taxa de estratificação de carbono orgânico em Latossolo Vermelho após dez anos sob dois sistemas de manejo. R. Bras. Ci. Solo, 28:1023-1031, 2004.

TORMENA, C.A.; SILVA, A.P. \& LIBARDI, P.L. Caracterização do intervalo hídrico ótimo de um Latossolo Roxo sob plantio direto. R. Bras. Ci. Solo, 22:573-581, 1998.

VIEIRA, M.L. \& KLEIN, V.A. Propriedades físico-hídricas de um Latossolo Vermelho submetido a diferentes sistemas de manejo. R. Bras. Ci. Solo, 31:1271-1280, 2007.

ZAMBOLIM, L; REIS, E.M. \& CASA, R.T. Doenças de plantas no sistema plantio direto. In: ZAMBOLIM, L., ed. Manejo integrado de fitossanidade: Cultivo protegido, pivô central e plantio direto. Viçosa, MG, 2001. p.257-274. 